\title{
Effects of soil and air temperature on growth, development and water use of tomatoes ${ }^{1}$
}

\author{
A. T. Abdelhafeez ${ }^{2}$, H. Harssema, G. Veri ${ }^{3}$ and K. Verkerk \\ Department of Horticulture, Agricultural University, Wageningen, the Netherlands
}

Received: 13 January 1971

\section{Summary}

The effect of soil and air temperature on growth, development and water use of tomatoes was studied in two series of trials. In one trial tomato plants were grown in a glasshouse without air temperature control at soil temperatures ranging from $14^{\circ}$ to $29^{\circ} \mathrm{C}$. In the other trial tomato plants were grown in phytotron glasshouses at constant air temperatures of $17^{\circ}, 21^{\circ}$ and $25^{\circ} \mathrm{C}$ and at soil temperatures ranging from $12^{\circ}$ to $30^{\circ} \mathrm{C}$.

Growth was reduced at soil temperatures below $17^{\circ} \mathrm{C}$ and at air temperatures below $20^{\circ} \mathrm{C}$. Generative development was not much influenced by soil temperature; a low air temperature resulted in a late, but relatively rich flowering. Water use increased at higher soil temperatures.

\section{Introduction}

Both soil and air temperature play an important role in the production of tomatoes. Much research has been carried out already on the influence of air temperature, but there is little information on the effect of soil temperature. Therefore, in the present trial more attention was paid to the effect of soil temperature than to that of air temperature.

\section{Materials and methods}

In the first week of April 1970, tomato seeds, cv. 'Moneymaker', were sown in wooden boxes in a glasshouse kept at a temperature of about $20^{\circ} \mathrm{C}$. Three weeks afterwards the seedlings were transplanted into 5-litre plastic pots. The pots were filled with a known quantity of a soil mixture, the surface of which was covered with a 2 -cm layer of fine gravel. Two sheets of white plastic were put on top of the pots in order to reduce evaporation.

After transplanting, the plants were divided into two groups. One group was moved to a glasshouse without air temperature control, the other to a phytotron glasshouse,

\footnotetext{
1 This article will also be published as Publication 352, Laboratorium voor Tuinbouwplantenteelt, Landbouwhogeschool, Wageningen, the Netherlands.

2 Present address: Faculty of Agriculture, University of Khartoum, Sudan.

3 Present address: Lab. of Plant Radio Biochemistry and Ecophysiology, Rome, Italy.
} 
where air temperature and relative humidity were controlled. Light conditions were natural in both sites. Wherever the word phytotron is mentioned in this article, it refers to the phytotron glasshouse with natural light conditions.

In the glasshouse air temperature ranged from $15^{\circ}-20^{\circ} \mathrm{C}$ by night to $20^{\circ}-25^{\circ} \mathrm{C}$ by day. Soil temperature was kept at $20^{\circ} \mathrm{C}$ for one week, after which a range of six temperatures from $14^{\circ}$ to $29^{\circ} \mathrm{C}$ was applied.

In the phytotron three compartments were used with constant air temperatures of $17^{\circ}, 21^{\circ}$ and $25^{\circ} \mathrm{C}$. Relative humidity was kept at such a level that the vapour pressure deficit was about $4.5 \mathrm{~mm} \mathrm{Hg}$ at each air temperature. The plants were put at $21^{\circ} \mathrm{C}$ air and soil tempcrature for one week, after which the three air temperatures were applied. At each air temperature, soil temperature was $5^{\circ} \mathrm{C}$ lower than, equal to, or $5^{\circ} \mathrm{C}$ higher than the air temperature.

Nine plants were grown at each temperature regime. Soil temperature was controlled by using Wisconsintanks.

Throughout the experiment the soil moisture was maintained between 100 and $80 \%$ of the available water content, which range is optimal for growth of tomato (Abdel Rahman et al., 1959a). The amount of water necessary to restore field capacity was determined by means of weighing, so that the water use of the plants could be followed throughout the experiment.

Plant length and number of flowers and fruits on each truss were recorded weekly. Leaf area and fresh and dry weight of different plant parts were determined three times: by harvesting nine additional plants at transplanting time, four plants per treatment after three weeks and five plants after six weeks at the indicated temperatures.

\section{Results}

\section{Plant length}

Fig. 1a shows plant length at weekly intervals. In general, growth rates increased during the first two weeks, remained more or less constant until the fourth wcek and decreased thereafter. The initial increase in plant length was greater at higher soil and air temperatures. Both the constant growth rate and the decrease at the end of the experiment were not markedly influenced by soil temperature, but we:e smallest at the lowest air temperature $\left(17^{\circ} \mathrm{C}\right)$.

\section{Leaf area}

Fig. $1 \mathrm{~b}$ shows the leaf area of the plants after three and after six weeks at the different temperatures. The glasshouse data show that soil temperatures below $20^{\circ} \mathrm{C}$ resulted in a relatively smaller total leaf area. Above $20^{\circ} \mathrm{C}$ no differences in leaf area were observed after three weeks, whereas after six weeks a slight decrease at the higher soil temperatures occurred. The phytotron data show a clear interaction between soil and air temperatures. The optimal leaf area occurred at equal soil and air temperatures. At soil temperatures above the air temperature the leaf area was slightly smaller, and at soil temperatures below the air temperature there was a pronounced decrease in leaf area.

\section{Dry weight}

Fig. 1c shows the dry weight of the above ground parts of the plants after three and after six weeks. In the latter case, the dry weight of the vegetative parts (the stems and 

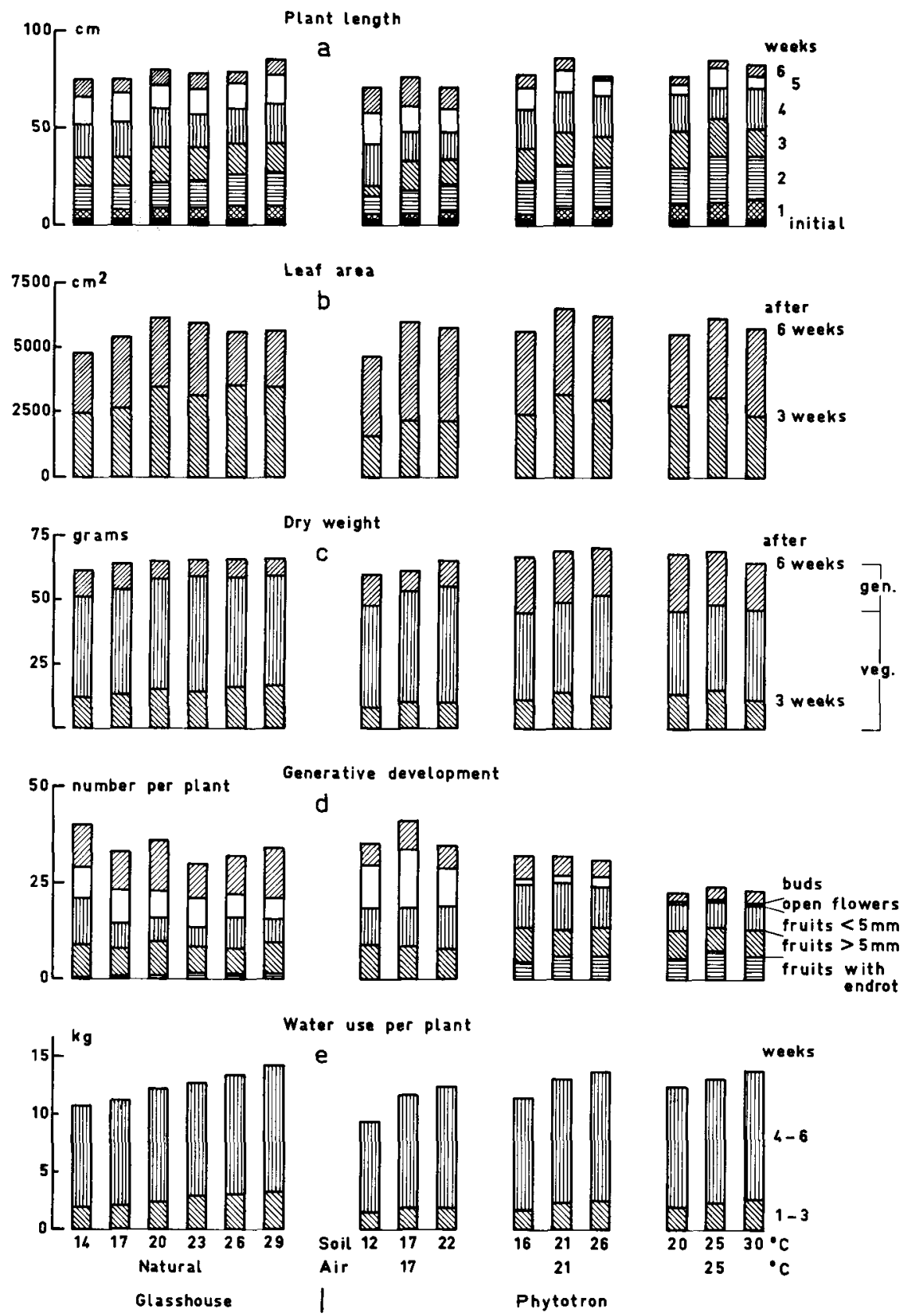

Fig. 1. Plant length, leaf area, dry weight, generative development and water use of tomato plants grown at the indicated soil and air temperatures. 
the leaves) and of the generative parts (the trusses with flowers and fruits) were separated. In general the total dry weight increased at increasing soil and air temperatures, differences being small above $20^{\circ} \mathrm{C}$. Only the combination of the highest soil and air temperature $\left(30^{\circ}\right.$ and $25^{\circ} \mathrm{C}$, respectively) resulted in a much lower dry weight.

Considering the dry weight of the vegetative parts only, the influence of the soil temperature was the same as that on total dry weight; the influence of the air temperature, however, was inverse: the higher the air temperature, the lower the dry weight of the vegetative parts. The dry weight of the generative parts was not influenced by soil temperature, but increased at the higher air temperatures due to a further stage in development.

\section{Generative development}

Considering the generative development it is useful to distinguish between earliness and capacity. Earliness may be defined as the quantity of fruits harvested before a certain time, capacity as the total yield expected. Taking the number of fruits larger than $5 \mathrm{~mm}$ as a measure for earliness, Fig. 1d shows that the soil temperature did not influence earliness, whereas an air temperature of $17^{\circ} \mathrm{C}$ reduced earliness. If the total number of fruits, flowers and buds is taken as a measure for capacity, higher air temperatures reduced capacity. No influence of the soil temperature is shown, except at the lowest soil temperature in the glasshouse and at $17^{\circ} \mathrm{C}$ soil and air temperature in the phytotron, where the capacity was relatively high.

Fig. 1d also shows, that quite a number of fruits was affected by endrot. It is not known whether the relatively high number of endrot fruits at the higher air temperatures was a direct effect of the air temperature or a result of the more advanced development of the fruits at these temperatures.

\section{Water use}

The water use per plant increased at higher soil and air temperatures, as is shown in Fig. 1e.

\section{Root system}

The soil, in which the plants were grown contained a rather high amount of peat, which rendered cleaning of the roots impossible. Therefore no quantitative measurements on the root system could be made. Fig. 2 shows, that roots grown at low soil temperatures were comparatively thicker, more white and less branched than those from higher soil temperatures.

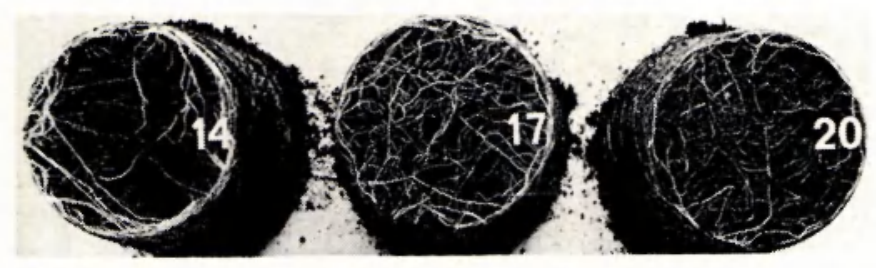

Fig. 2. Root development of plants, grown at the indicated soil temperatures and at natural glasshouse air temperatures. 


\section{Discussion}

\section{Growth and development}

The effect of soil temperature on growth was most evident during the first and the second week. Soil temperatures below $20^{\circ} \mathrm{C}$ reduced growth, whereas the differences between the effects of soil temperatures in the range of $20^{\circ}$ to $30^{\circ} \mathrm{C}$ were only small and irregular. This result is in accordance with that of Fujishige and Sugiyama (1968), whereas Abdel Rahman et al. (1959b) reported a linear increase of leaf area with increasing soil temperatures between $17^{\circ}$ and $30^{\circ} \mathrm{C}$. An air temperature of $17^{\circ} \mathrm{C}$ also reduced growth during this period, compared with $21^{\circ}$ and $25^{\circ} \mathrm{C}$.

The generative development was not markedly influenced by soil temperature, but low air temperatures comparatively retarded truss development. After three weeks there were no open flowers in the glasshouse and in the phytotron compartment with an air temperature of $17^{\circ} \mathrm{C}$. At air temperatures of $21^{\circ}$ and $25^{\circ} \mathrm{C}$ the percentage of open flowers in the first truss was 15 and 50, respectively.

During the last three weeks the total dry-weight increase was not affected by the soil temperature and only slightly by the air temperature, being relatively low at $17^{\circ} \mathrm{C}$. Probably because of the increased earliness at higher air temperatures a greater part of the dry matter produced was used for fruit development, resulting in a strongly reduced vegetative growth at the higher air temperatures. As a consequence, plants at $21^{\circ}$ and $25^{\circ} \mathrm{C}$ showed relatively thin stems (see Table 1) and the yielding capacity was reduced. Obviously, constant air temperatures of $21^{\circ} \mathrm{C}$ or higher forced the tomato plants into such a quick development, that a favourable balance between vegetative and generative growth, needed for a crop, was lost. A similar effect of air temperature on earliness and capacity was reported by Abdelhafeez and Verkerk (1969).

\section{Water relations}

The water use per plant was higher at higher soil and air temperatures. These differences may be caused by several factors, the most important of which are: different evaporation conditions, differences in leaf area, differences in root extension and differences in the resistance of water transport through the roots.

Table 1. Sturdiness of stems of tomato plants grown at different soil and air temperatures for six weeks, expressed as dry weight per unit length.

\begin{tabular}{|c|c|c|c|c|}
\hline \multicolumn{2}{|l|}{ Glasshouse } & \multicolumn{3}{|l|}{ Phytotron } \\
\hline $\begin{array}{l}\text { soil temp. } \\
\left({ }^{\circ} \mathrm{C}\right)\end{array}$ & $\begin{array}{l}\text { sturdiness } \\
(\mathrm{g} / \mathrm{cm})\end{array}$ & $\begin{array}{l}\text { air temp. } \\
\left({ }^{\circ} \mathrm{C}\right)\end{array}$ & $\begin{array}{l}\text { soil temp. } \\
\left({ }^{\circ} \mathrm{C}\right)\end{array}$ & $\begin{array}{l}\text { sturdiness } \\
(\mathrm{g} / \mathrm{cm})\end{array}$ \\
\hline 14 & 0.19 & 17 & 12 & 0.19 \\
\hline 17 & 0.20 & & 17 & 0.20 \\
\hline 20 & 0.20 & & 22 & 0.20 \\
\hline 23 & 0.19 & & & \\
\hline 26 & 0.20 & & 16 & 0.16 \\
\hline \multirow[t]{5}{*}{29} & 0.21 & 21 & 21 & 0.16 \\
\hline & & & 26 & 0.18 \\
\hline & & & 20 & 0.16 \\
\hline & & 25 & 25 & 0.15 \\
\hline & & & 30 & 0.15 \\
\hline
\end{tabular}


Evaporation conditions. The relative humidity in the phytotron was maintained at a higher level in the rooms with a higher air temperature in order to achieve in each room an equal saturation deficit. As radiation and air movement were also nearly the same, the evaporation conditions should not be affected by differences in air temperature. In fact no significant differences were observed between the evaporation of water from petri-dishes in the various rooms. Evaporation conditions in the glasshouse cannot be compared with those in the phytotron, because both temperature and relative humidity were not controlled.
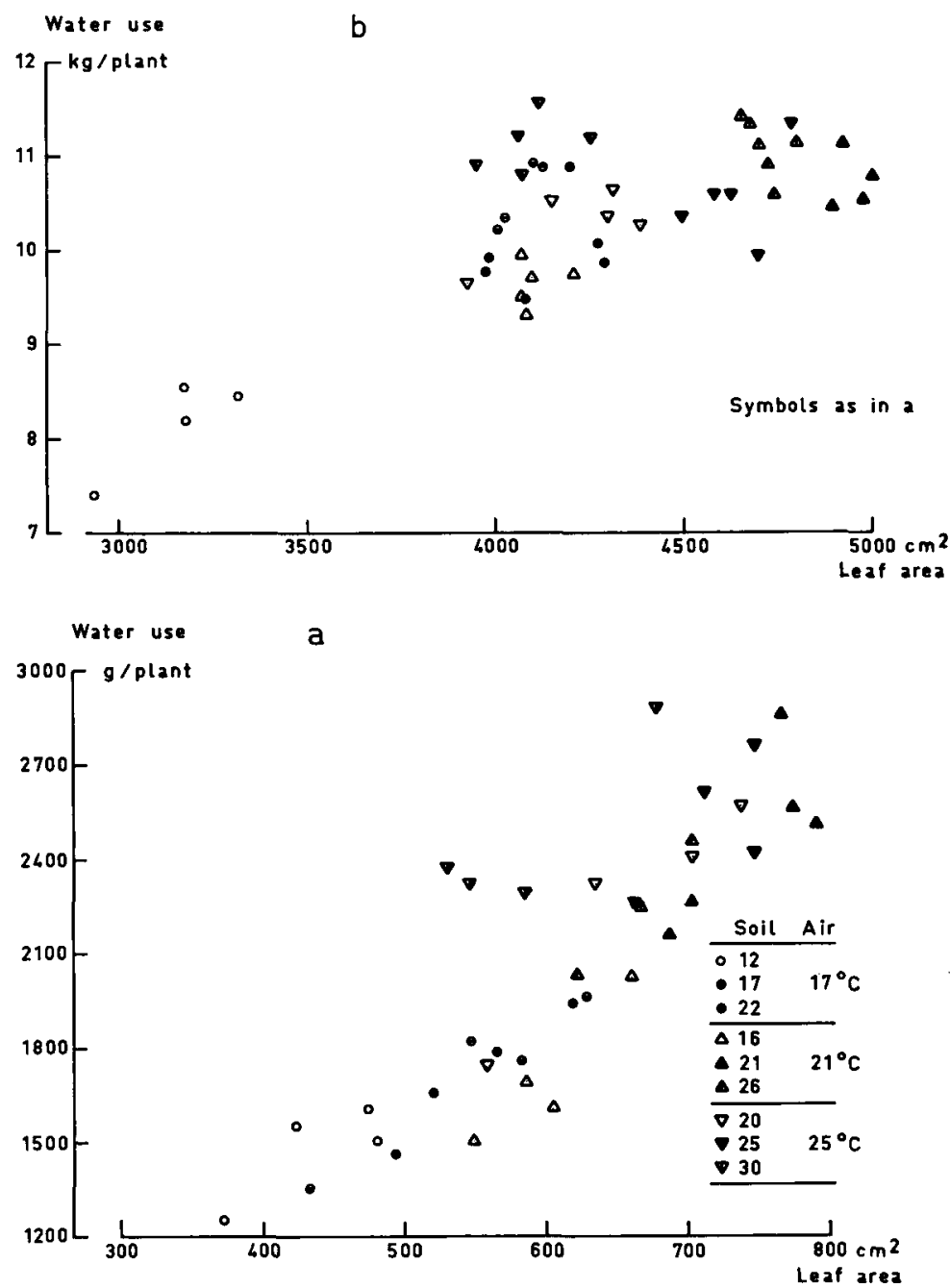

Fig. 3. Transpiration per plant related to the leaf area per plant;

a. for the first period of three weeks, b. for the second period of three weeks. 
Leaf area. Generally there is a linear relationship between transpiration and leaf area, when the leaf area index is low. At higher values, the transpiration per plant is independent of the leaf area.

For the first period of three weeks an average leaf area was calculated by assuming exponential growth during this period, from: $\bar{A}=\left(\mathbf{A}_{2}-\mathbf{A}_{1}\right):\left(\ln \mathbf{A}_{2}-\ln \mathrm{A}_{1}\right)$, in which $A_{1}$ and $A_{2}$ are the leaf area at the beginning and at the end of the period, respectively. The exponential growth was concluded from the increasing growth rate during this period, shown in Fig. 1a. The average leaf area index ranged from 0.8 to 1.5, suggesting that a correlation could exist between leaf area and transpiration per plant, during this period. Fig. 3a shows that this correlation did exist within each set of four plants at the same temperature regime. So, the higher transpiration per plant at higher soil and air temperatures during this period is, at least partly, due to an increased leaf area per plant.

For the second period of three weeks the average leaf area per plant was calculated by assuming linear growth during this period from: $\bar{A}=1 / 2\left(A_{1}+A_{2}\right)$. This linearity is concluded from the more or less constant increase in plant length during this period; anyhow, deviations from linearity do not substantially change the conclusions to be drawn. The average leaf area index was between 3 and 5 during this period, and Fig. $3 \mathrm{~b}$ shows, that, within each set of five plants at the same temperature, the transpiration per plant was independent of the leaf area, except for the plants at $21^{\circ} \mathrm{C}$ soil temperature. For this period, therefore, a higher transpiration rate at higher temperatures is not caused by differences in the leaf area per plant.

Root extension. Root extension was influenced to some extend by soil temperature, ut no quantitive measurements could be taken.

$\Lambda$ sistance of water transport. The influence of the leaf area on the transpiration per plant during the first period of three weeks can be eliminated by calculating the transpiration per unit leaf area The remaining effect of soil temperature, visualized in Fig. $4 \mathrm{a}$ and $4 \mathrm{~b}$ shows a $\mathrm{Q}_{10}$-value of 1.1 to 1.2 , which is about the same as that for the viscosity of water. This suggests, that the increasing viscosity of water at lower temperatures is the only direct cause of the reduced transpiration. However, Abdel Rahman et al. (1959b) concluded from their experiments, that besides the increasing viscosity of water, a decreasing 'root-permeability' caused the reduction of transpiration at lower soil temperatures.

As dry matter production is less influenced by soil temperature than transpiration, the transpiration coefficient increases at higher soil temperatures (Fig. 4c).

An increase in the root resistance at low soil temperatures does not necessarily reduce transpiration, because the root resistance is only a small part of the total resistance in the pathway of water from soil to atmosphere. Without an effective increase in resistance in the gaseous phase of this pathway, transpiration will continue at the same rate with an increase in suction gradient until the plant is air-dry. Attempts have been made therefore, to obtain data of stomatal resistance at different soil temperatures. Because of the difficulties in using the massflow porometer (Bierhuizen et al., 1965) with hairly leaves of tomato, quantitative conclusions could not be drawn from these measurements. In Fig. 5 an example is shown of the stomatal resistance (in arbitrary scale) of tomato plants grown at $12^{\circ}$ and $22^{\circ} \mathrm{C}$ soil temperature, at two-hourly intervals during a sunny day. During the early hours of the day, plants at both soil temperatures $\left(12^{\circ}\right.$ and $\left.22^{\circ} \mathrm{C}\right)$ were able to absorb water at such a rate to meet the trans- 


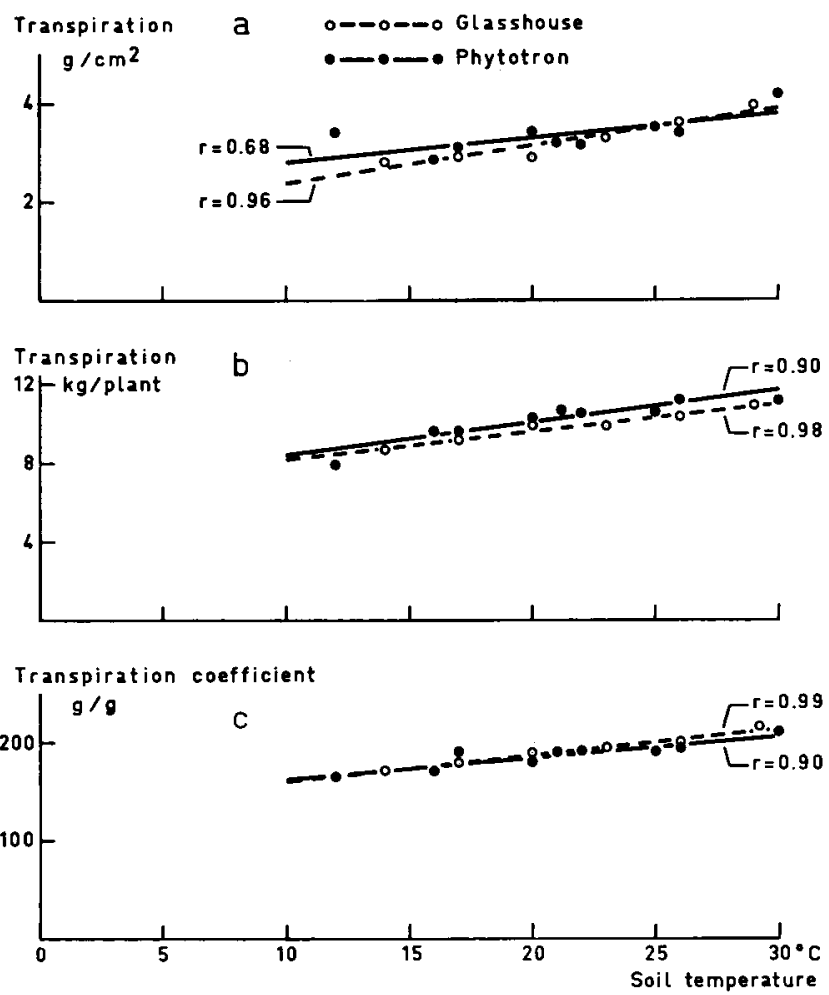

Fig. 4a. Transpiration per unit leaf area during first period of three weeks, at various soil temperatures;

b. Transpiration per plant during second period of three weeks, at various soil temperatures;

c. Transpiration coefficient for the whole experimental period, at various soil temperatures.

piration losses. However, early in the afternoon a time lag - between water uptake and transpiration - developed resulting in a pronounced stomatal closure of plants at $12^{\circ} \mathrm{C}$. Late in the afternoon when the evaporative conditions became milder the stomates of these plants reopened. The plants at $22^{\circ} \mathrm{C}$, apparently, could maintain a favourable water balance during the day without stomatal closure.

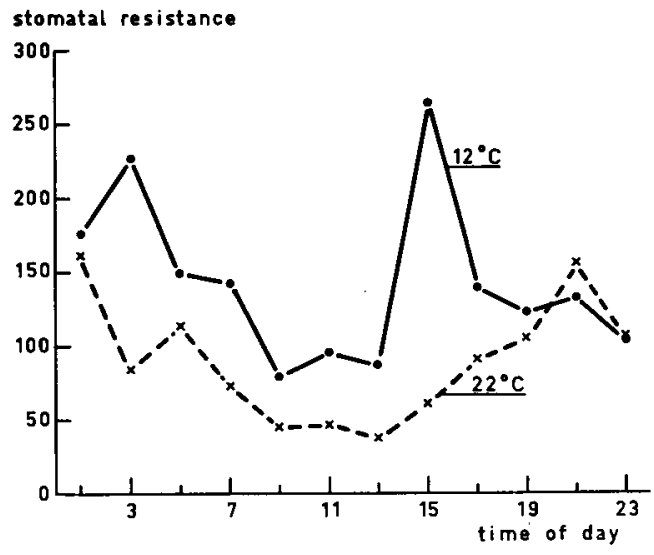

Fig. 5. Example of the daily course of stomatal resistance of plants, growing at 12 and $22^{\circ} \mathrm{C}$ soil temperature. 


\section{References}

Abdelhafeez, A. T. \& K. Verkerk, 1969. Effects of temperature and water-regime on the emergence and yield of tomatoes. Neth. J. Agric. Sci. 17: 50-59.

Abdel Rahman, A. A., P. J. C. Kuiper \& J. F. Bierhuizen, 1959a. Preliminary observations on the effect of light intensity and photoperiod on transpiration and growth of young tomato plants under ccontrolled conditions. Meded. LandbHogesch. Wageningen 59 (11) 1-12.

Abdel Rahman, A. A., P. J. C. Kuiper \& J. F. Bierhuizen, 1959b. Preliminary observations on the effect of soil temperature on transpiration and growth of young tomato plants under controlled conditions. Meded. LandbHogesch. Wageningen 59 (15) 1-12.

Bierhuizen, J. F., R. O. Slatyer \& C. W. Rose, 1965. A porometer for laboratory and field operation. J. exp. Bot. 16: 182-192.

Fujishige, N. \& T. Sugiyama, 1968. Effect of soil temperature on growth of seedlings of a few fruit vegetables (a preliminary report). J. Jap. Soc. hort. Sci. 37: 221-226. 